\title{
Moving the needle on the university of third age in Malaysia: recent developments and prospects
}

\begin{abstract}
In the 2015 population projections released by the Department of Statistics Malaysia, 2.9 million or $9.2 \%$ of the total 31.4 million population is aged 60 years or over. Median age of the population has increased from 17 years in 1970 to 30 years in 2020. By any measure, Malaysia is a rapidly ageing society, and this poses significant opportunities and challenges for the multi-ethnic democracy in an open, modern economy. Since the 9th Malaysia Plan (2006-2010), the government has highlighted the need to change "from a welfare approach to a development approach to ensure active and productive ageing". Lifelong learning in Malaysia is still focused primarily on skills retraining and vocational education, although it should be noted that there are many religious and social groups that have served the interests of older persons. Before Older Person Activity Centres, there are many senior citizen clubs providing leisurely activities and religious schools offering Islamic studies for older Muslims. The University of the Third Age programme in Malaysia renewed a focus on learning in later life and promoted a model where older persons themselves organise their own learning activities. As such, the three U3As or lifelong learning associations for older persons are not just running courses, but also managing the affairs of their own organisation. Coherence and understanding of the goals and purposes of U3As in Malaysia must be shared so that there is a broad buy-in of the initial, founding ideals. The existence of a peak body such as the Third Age Trust in UK can help coordinate, monitor and support the development of the U3As in Malaysia. The government should seek to level the playing field and promote, as well as reward, lifelong learning activities that are sustainable, effective and receptive to the needs of older Malaysians throughout the country. As the young lifelong learning associations in the country mature and stabilise, only time can tell if the U3A brand or model will survive and flourish in a new Malaysia.
\end{abstract}

Keywords; University of the third age; Active ageing; Lifelong learning; Geragogy; Malaysia 